\title{
Accuracy of mRNA HPV Tests for Triage of Precursor Lesions and Cervical Cancer: A Systematic Review and Meta-Analysis
}

\author{
Ana Cristina L. Macedo (iD), ${ }^{1}$ João Carlos N. Gonçalves, ${ }^{1}$ Daniela Vicente Bavaresco, ${ }^{1}$ \\ Antonio José Grande, ${ }^{2}$ Napoleão Chiaramonte Silva, ${ }^{1}$ and Maria Inês Rosa $\oplus^{1}$ \\ ${ }^{1}$ Translational Biomedicine Laboratory, Graduate Program in Health Sciences, \\ University of Southern Santa Catarina (UNESC), Criciúma, SC, Brazil \\ ${ }^{2}$ Laboratory of Evidence in Health, Medicine and Health Sciences, University of State of Mato Grosso do Sul, \\ Campo Grande, MS, Brazil
}

Correspondence should be addressed to Maria Inês Rosa; mir@unesc.net

Received 30 July 2018; Accepted 26 May 2019; Published 11 June 2019

Academic Editor: Akira Hara

Copyright (C) 2019 Ana Cristina L. Macedo et al. This is an open access article distributed under the Creative Commons Attribution License, which permits unrestricted use, distribution, and reproduction in any medium, provided the original work is properly cited.

Objective. This systematic review evaluates the accuracy of the mRNA HPV biomarker in cervical smears to identify cervical intraepithelial neoplasia (CIN) 2 or 3 and cervical cancer. Data Source. Eligible studies were identified by performing a search of electronic databases on Medline via Pubmed, Lilacs, Cochrane Library, Embase, and Grey literature for papers published between January 1990 and June 2018. Study Eligibility Criteria. As no randomized studies were identified, this review focuses on observational studies in which the mRNA HPV diagnostic test was compared to a histopathology reference standard. We analyzed studies that included women screened for cervical cancer using mRNA HPV. Study Appraisal and Synthesis Methods. After screening, 61 studies including 29,674 patients met the inclusion criteria and were analyzed. Dichotomization was performed by defining CIN2 or worse (CIN2+) versus CIN1, HPV infection, and normal (CIN 1-). The analysis was discriminated by the following tests: Aptima, PreTect HPV Profeer, NucliSens EasyQ HPV, OncoTect, and Quantivirus. Results. Analyzing by technique, Aptima, with 28 studies, exhibited superior performance, showing for the outcomes CIN2+ and CIN3+ an AUC of 0.88 (0.82-0.95) and 0.91 (0.84-0.99), a pooled sensitivity of $92.8 \%$ (95\%CI 91.9-93.7) and 95.6\% (95\%CI 94.5-96.5), and a pooled specificity of 60.5\% (95\%CI 59.8-61.3) and $61.9 \%$ (95\%CI 61.1-62.7), respectively. Conclusion. This study supports the current hypothesis that the mRNA HPV assay is an adequate tool for secondary cervical cancer screening.

\section{Introduction}

Cervical cancer is the third most common malignancy in women and fourth in mortality worldwide. In 2012, there were 406,210 diagnosed cases and 265,672 deaths [1]. In the United States, there were 12,578 new cases and 4,115 deaths in 2014 [2]. Of note, screening tests for cervical cancer make this disease one of the most easily preventable malignant tumors. Worldwide, cervical cancer screening is accomplished using the Papanicolaou test, which looks for cytological abnormalities. If identified, the patient will be referred for colposcopy and targeted biopsies. Given consensus regarding the causal role of high-risk human papillomavirus (HR HPV) in the development of cervical cancer [3], DNA hrHPV assays have been incorporated as a screening method in some developed countries [4-6]. HPV is the number one most common infectious agent related to cancer development in women, and it is estimated that 570,000 cases of cancer arose from this infection in 2012, including anogenital and oropharynx cancers. Currently, the following HPV strains are considered high risk with respect to cervical cancer development: 16, 18, $31,33,35,39,45,51,52,56,58$, and $59[1,7]$.

Screening strategies should balance potential benefits and potential harm from intervention. DNA hrHPV tests exhibit high sensitivity with low specificity when the outcome is a precancerous lesion $[4,6]$. Maintaining a 3-year interval between screening visits is a good safety measure, but it increases unnecessary routing to colposcopy with a potential 
rise in cost and overtreatment $[4,6]$. As a result, some countries are adopting a 5-year interval $[4,6]$. In this scenario, an assay with good accuracy and improved specificity should be associated with or used alone in primary screening. Previous studies reported that mRNA HPV tests, which reveal current HPV oncogene expression and evidence of its deregulation per detection of viral proteins, possess these characteristics $[66,67]$.

The present systematic review assesses the accuracy of mRNA HPV tests globally that have been submitted to sensitivity analysis and, when available, compared with the DNA hrHPV test and cytology. The prespecified hypothesis is that mRNA HPV exhibits acceptable accuracy and high specificity for detection of high-grade squamous intraepithelial lesion (HSIL) or cervical intraepithelial neoplasia (CIN) 2 or 3, precancerous lesions, and cervical cancer.

\section{Methods}

We performed a systematic review according to a prospective protocol using PRISMA statement guidelines. This review protocol is registered at PROSPERO (International prospective register of systemic reviews, http://www.crd.york.ac .uk/prospero; CRD 2015: CRD42015020232).

2.1. Identification of Studies. Eligible studies were identified by performing a search of electronic databases on Medline via Pubmed, Lilacs, Cochrane Library, Embase, and Grey for papers published from January 1990 to October 2017. A search on clinical trials was not performed because this database includes intervention trials and is used primarily for intervention systematic reviews and not for diagnostic reviews. The medical subject headings $(\mathrm{MeSH})$ and text words for the terms: "cervical cancer", "cervical dysplasia", "squamous intraepithelial lesion", "cervical intraepithelial neoplasia", "CIN", "screening" and "RNAm HPV" were entered. No language restrictions applied. Reference lists of all available primary studies were reviewed to identify additional relevant citations.

2.2. Study Selection. As no randomized studies were identified, this review focused on observational studies in which the mRNA HPV diagnostic test was compared to a histopathological reference standard. All included studies were crosssectional or, if cohort study, it was included only if biomarkers, cytology, and histopathology have been available in baseline, to characterize a cross-sectional data.

2.3. Patients. We analyzed studies that included women who were screened for cervical cancer in secondary settings, that is, testing performed after someone has had an abnormal result by cytology or HPV testing. When the study was originally from primary screening, only the sample with abnormalities and that had been forwarded to colposcopy was considered. Additionally, when only considering samples submitted for colposcopy, whenever possible, only biopsied samples were included. These variables were subsequently considered in the sensitivity analysis.
2.4. Index Test. The index test was an mRNA HPV test from a sampling of a cervical smear. Positive and negative reads were assigned according to the cut-off points proposed by the manufacturers.

As alternative tests, the accuracy of DNA hrHPV tests was extracted when applied to the same sample used for the mRNA test.

The exclusion criteria for index tests applied in tissue fragments. Studies in which all specimens were diagnosed as cancer were excluded, since there were no false positives or true negatives.

2.5. Reference Standard. The reference test was histologic evaluation of tissue in paraffin-embedded sections using the same Bethesda System classification.

2.6. Data Extraction. This study was independently reviewed by two investigators (MIR, ACM). Disagreements with regard to study inclusion or exclusion were initially resolved by consensus. When consensus was not attained, disagreements were resolved by a third reviewer (JCG).

2.7. Assessment of Methodological Quality. Methodological quality assessment of studies for diagnostic accuracy was performed according to criteria from the Quality Assessment of Diagnostic Accuracy Studies (QUADAS-2). These criteria assess the quality of included studies in terms of risk of bias and concerns regarding applicability over four domains [68].

2.8. Statistical Analysis. A 2 x 2 contingency table was constructed for each selected study. Rates were calculated as true positive (TP), false positive (FP), true negative (TN), and false negative (FN). When any cell containing " 0 " was present in the contingency table, 0.5 was added to all cells in all studies to facilitate calculations. Dichotomization of the contingency tables was performed by defining two categories: (1) CIN2 or worse versus CIN 1 and normal and (2) CIN 3 or worse versus CIN1 and normal (excluding CIN2 from the analysis, since we do not believe that CIN2 can be seen as a false positive).

For all studies, we calculated the true-positive rate (TPR; sensitivity), specificity, false-positive rate (FPR; 1 - specificity), and the diagnostic odds ratio (DOR). The DOR, which relates to different combinations of sensitivity and specificity, was calculated by (sensitivity/(1-specificity))/((1sensitivity)/specificity)) [69]. A DOR $>1$ indicated the assay had discriminative power. The DOR describes the odds of the positive test results in participants with disease compared with the odds of positive test results in those without disease. Bivariate analysis was used to calculate pooled estimates of sensitivity, specificity, and DOR with 95\% confidence intervals (CIs) for summary estimates [70].

To analyze the accuracy of HPV mRNA, the area under the curve (AUC) was calculated from the hierarchical summary receiver-operator curves (HSROC). AUC values $\geq 0.5$, $0.75,0.93$, and 0.97 were considered to represent fair, good, very good, and excellent accuracy, respectively [71].

Heterogeneity of both sensitivity and specificity across the studies was tested using a $\chi^{2}$ analysis, with a $\chi^{2}$ p-value $<$ 


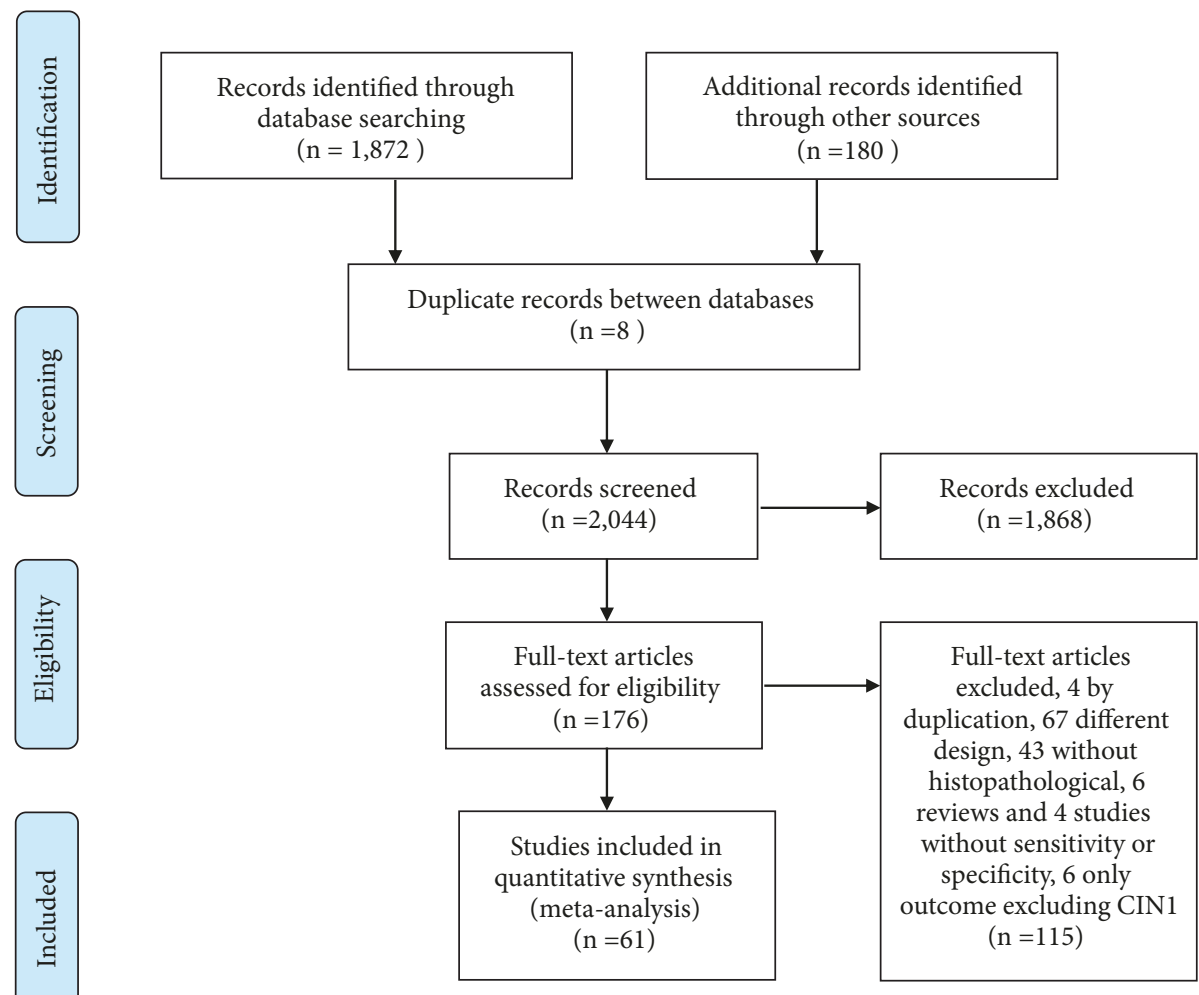

FIGURE 1: PRISMA Flowchart of the search strategy.

0.05 considered heterogeneous. As an alternative method to explore heterogeneity, the $\mathrm{I}^{2}$ index was also utilized. The $\mathrm{I}^{2}$ index presents the percentage of total variation across studies due to heterogeneity rather than chance; $\mathrm{I}^{2}$ values of $75 \%$ or greater were considered substantial heterogeneity [70].

To analyze publication bias, inverted funnel plots of the logarithmic odds ratio (OR) of individual studies were plotted against the sample size. The robustness of the results was tested by repeating the analysis with a different statistical model (random effects model). The meta-analysis was performed using Metadisc ${ }^{\circledR}$ and Review Manager ${ }^{\circledR}$ (RevMan) version 5.2 software $[72,73]$.

\section{Results}

3.1. Study Identification and Eligibility. Among the 2,052 studies identified from electronic database searches and reference lists, we excluded 1,868 published studies through title and abstract screening (Figure 1). One hundred seventy-six fulltext studies were then retrieved. Of those, 107 studies were excluded after further scrutiny. A complete list of excluded studies is available from the authors.

3.2. Study Descriptions. Sixty-one primary studies were included $[8-65,74-76]$ in cytology secondary analyses. Of the main analysis, 60 studies informed the major outcome, CIN1vs. CIN2+, and 39 studies have shown CIN1- vs. CIN3+. A total of 29,674 patients met the criteria for inclusion and were analyzed. The main characteristics of the included studies are shown in Table 1 . Table 2 shows the sum contingency tables with regard to the different techniques applied for CIN1- vs. CIN2+ and CIN1- vs. CIN3+. The contingency tables per study may be requested from the authors.

3.3. Quality Assessment. QUADAS-2 was performed considering the following categories: index and reference test, flow, and timing (Figure 2). For the index and reference test, most studies did not mention blinding of the pathologists and were classified as "unclear." In $37.7 \%$, the verification of the histopathological examination was partial; that is, women with normal colposcopy were not biopsied, as shown in Table 1 . In addition, all included studies used a histopathological test as a reference, and the index tests were clearly cited. Therefore, "concern" with these items was low. For flow and timing, six studies did not cite the interval between the index and referenced tests [12, 24, 25, 35, 37, 75], and in one, the interval was considered inadequate because it was from a cohort that did not show separate baseline and follow-up results [27]. In cohort studies, we considered the results of the baseline whenever possible.

3.4. Accuracy of HPV mRNA. The accuracy (sensitivity, specificity, AUC, DOR, and sum contingency tables) of HPV mRNA tests stratified by kit identified in this systematic review is discriminated in Table 2 . 


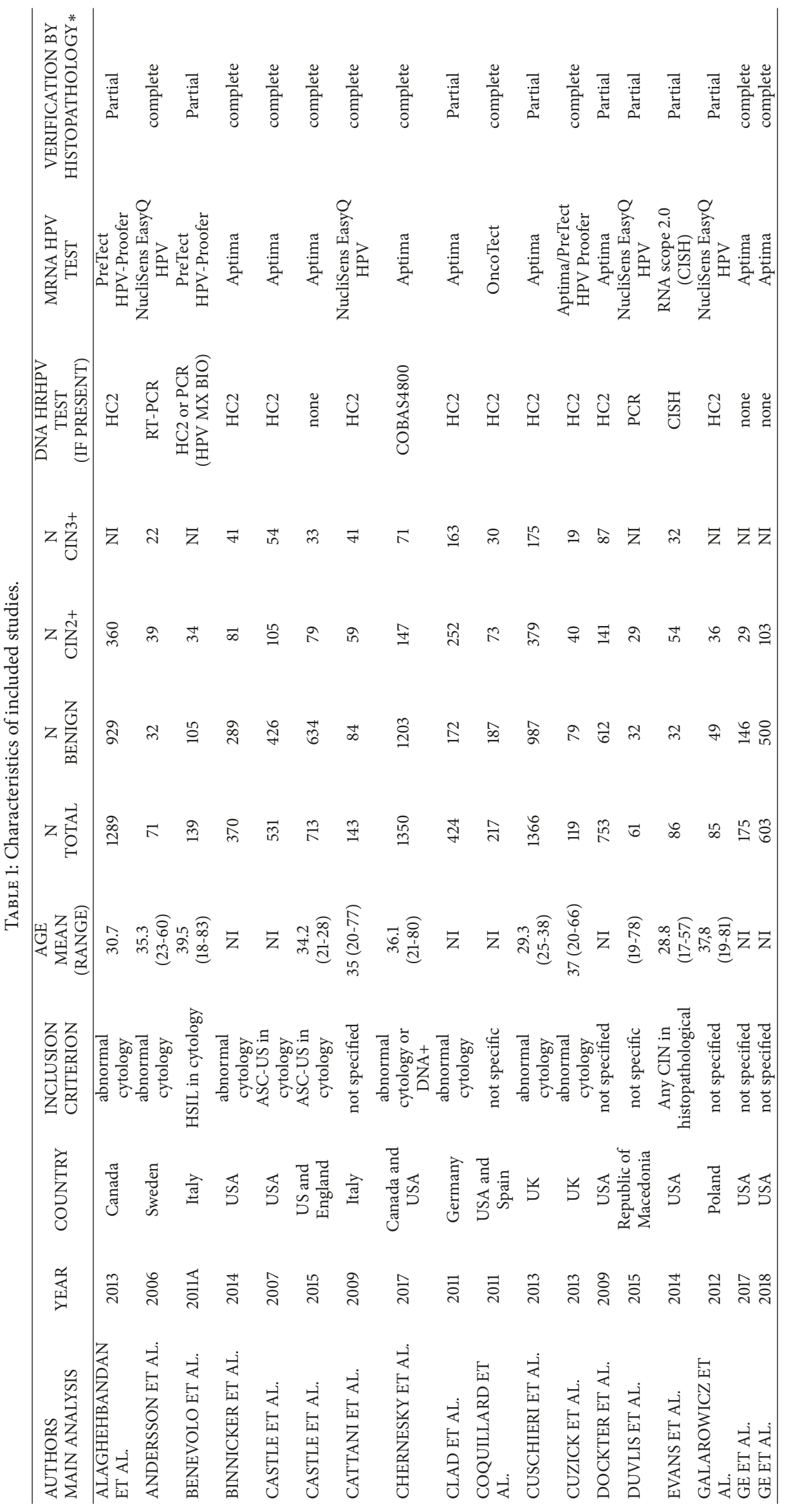




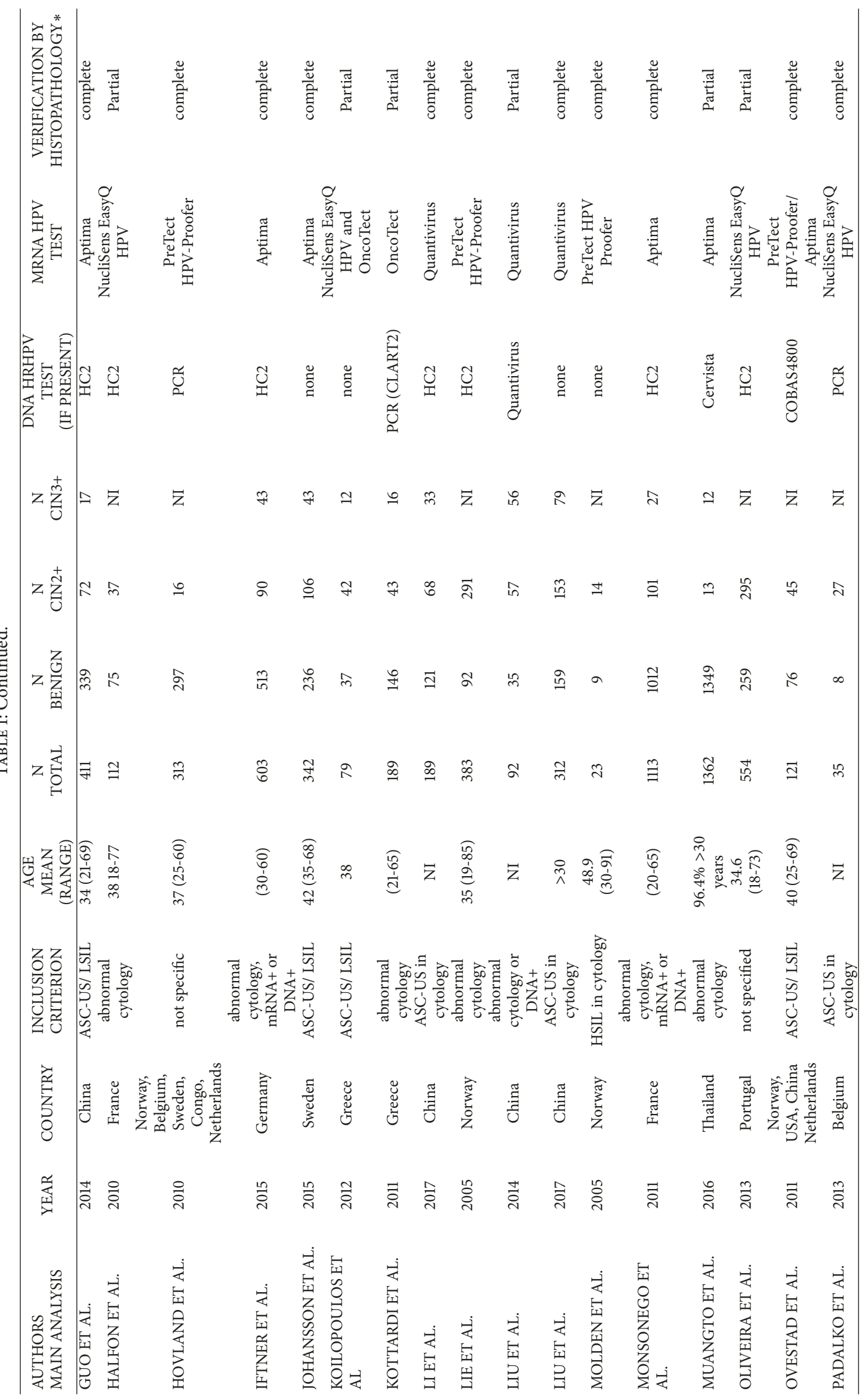




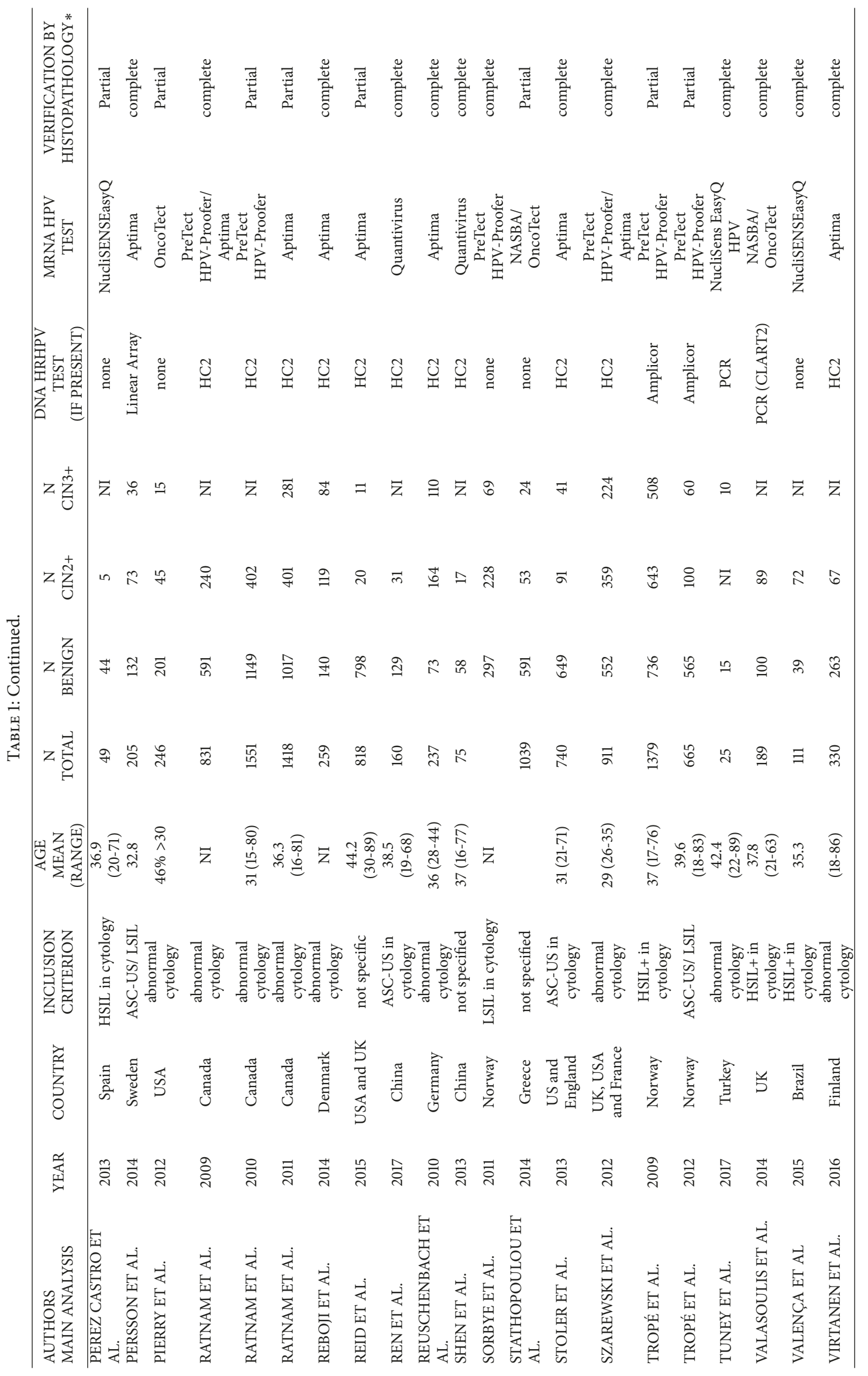




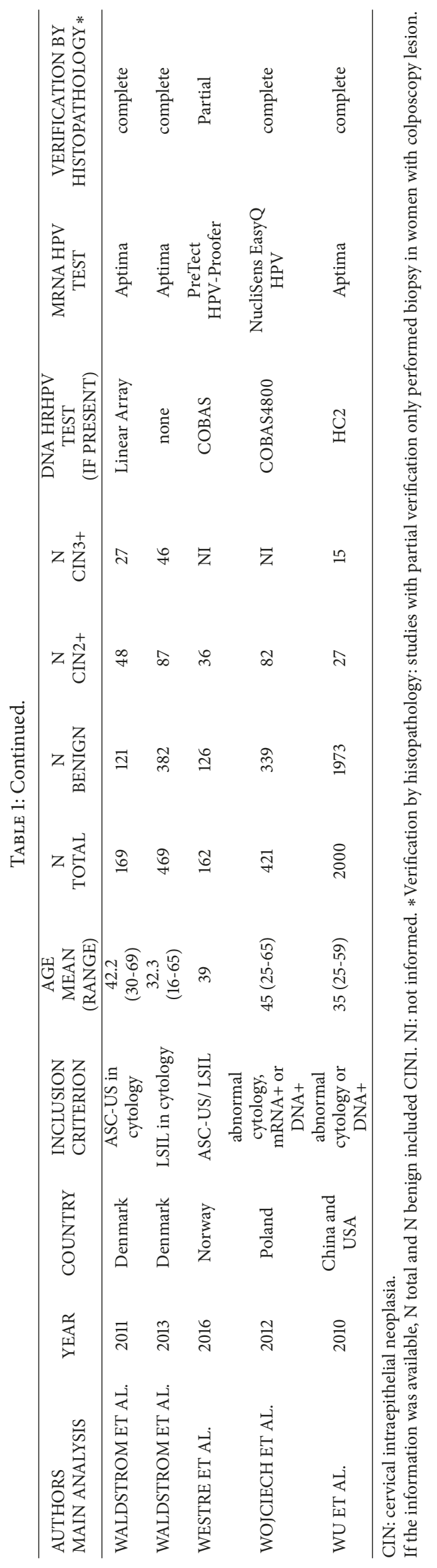




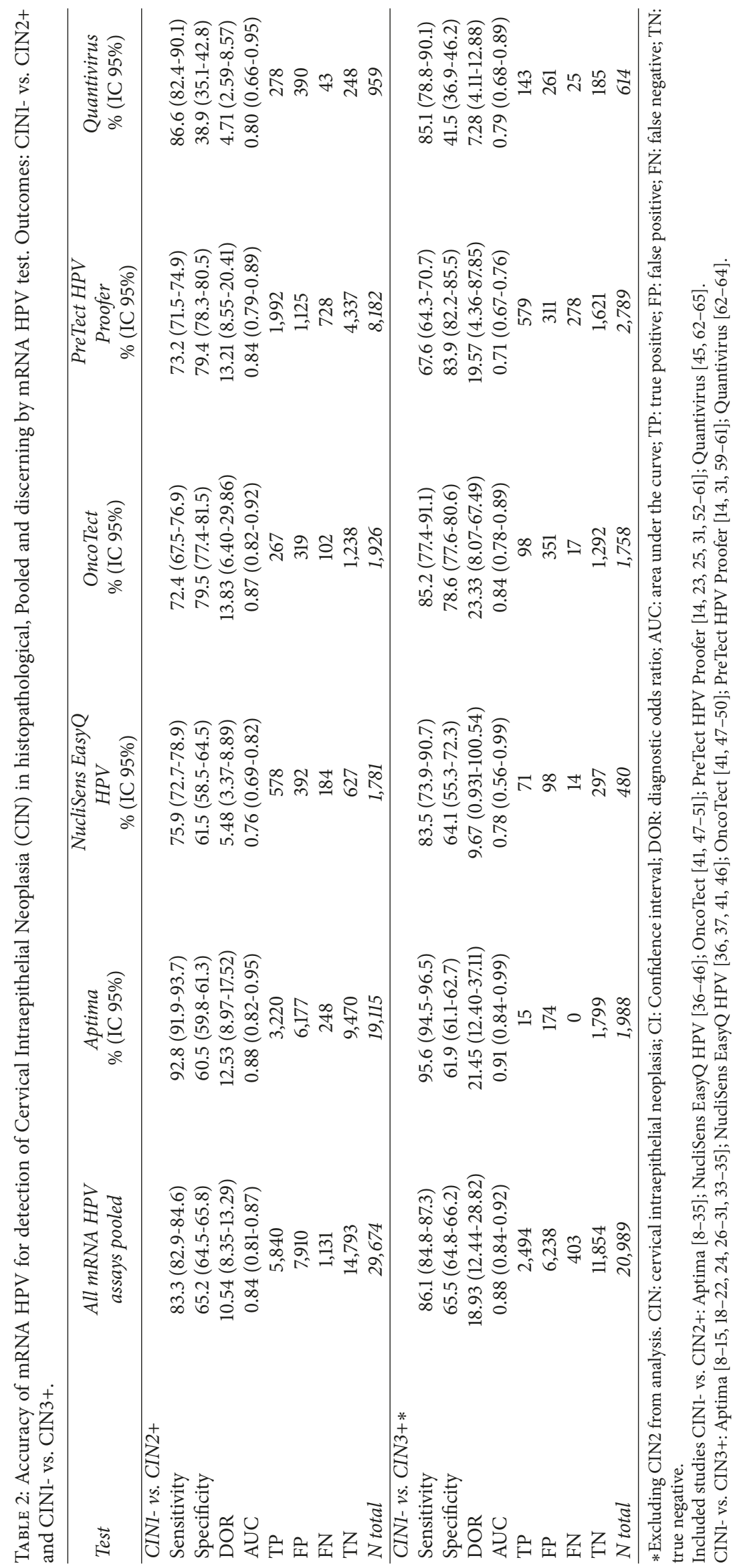




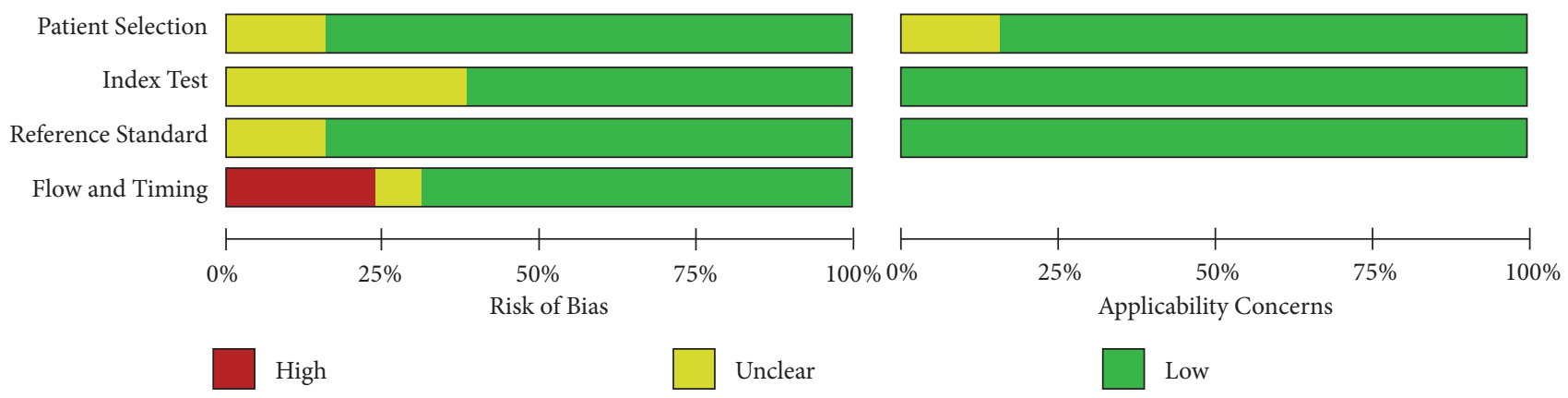

FIgURE 2: Quality Assessment of Diagnostic Accuracy Studies (QUADAS-2).

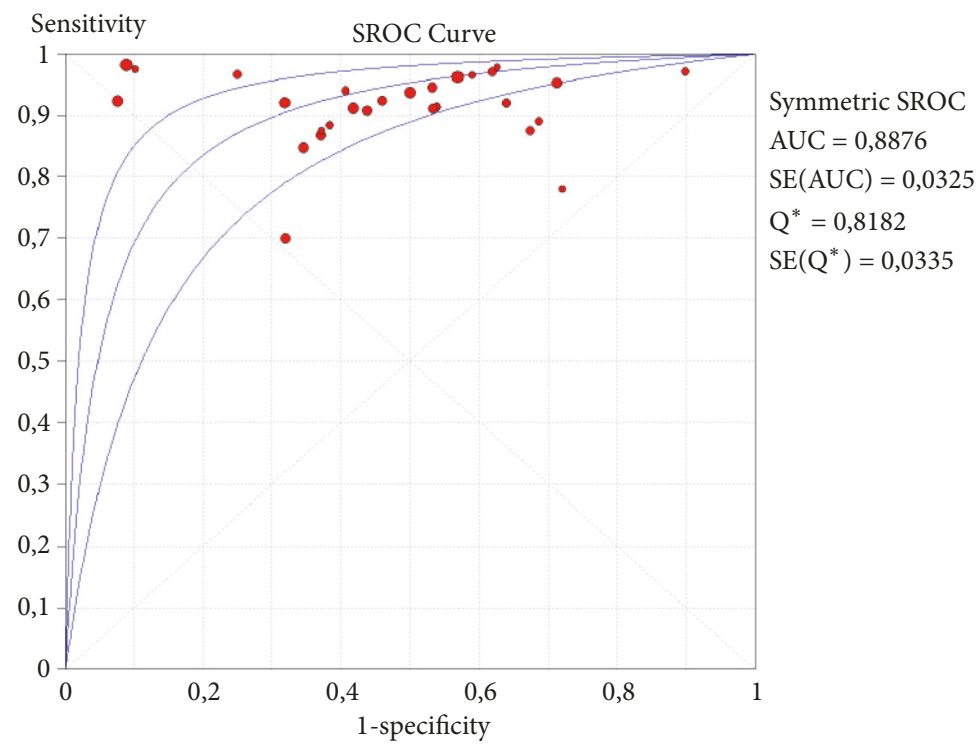

FIGURE 3: Forest plot of sensitivity and specificity of cervical cytology.

Different techniques are available, based on identification of HPV mRNA transcription, mainly of E6 and E7 oncogenes. In this systematic review, five main tests were identified. Aptima (Hologic Gen-Probe, San Diego, CA, USA) is a target amplification assay utilizing transcription-mediated amplification (TMA) for qualitative detection of viral polycistronic E6/E7 mRNA from 14 high-risk HPV types [77]. PreTect HPV-Proofer (NorChip AS, Klokkarstua, Norway) is a real-time multiplex assay that uses nucleic acid sequencebased amplification (NASBA), a sensitive transcription-based amplification system (TAS) for the specific in vitro replication of mRNA. NucliSens EasyQ HPV (bioMérieux, The Netherlands) is based on the original PreTect Proofer assay with the addition of the NucliSENS hardware platform and the software for NASBA measurements and data analysis, both identifying the same five most frequently recognized HPV types [78]. OncoTect (IncellDxTM, Inc. Menlo Park, CA, USA) combines two techniques, called in situ hybridization and flow cytometry. Finally, the Quantivirus HPV E6/E7 RNA 3.0 assay (DiaCarta, Hayward, CA, USA) detects E6/E7 mRNA of 13 high-risk and 6 low-risk types and is a sandwich nucleic acid hybridization procedure using chemiluminescent detection of mRNA molecules that are hybridized to DNA probes [65]. Aptima, with 28 studies, exhibited superior performance, with the best sensitivity, near from Hybrid Capture 2, and higher specificity, comparing to this assay, as shown ahead. Its SROC is shown in Figure 3.

We considered the importance of describing the results divided by age; however, few studies [13, 49] discriminated between the over and under 30 years of age category, and there were no important differences in this small sample (data not shown).

3.5. Comparing HPV mRNA to hrHPV DNA. Some studies applied two or more assays to the same sample, making it possible to compare them. In the outcome CIN1- vs. CIN2+, comparing Aptima to Hybrid Capture 2 (HC2, Qiagen, Gaithesburg, MD, USA), a DNA hrHPV test, fourteen studies were available $[8,12-14,19,20,25-29,31,32,35]$. The pooled sensitivity identified was $93.9 \%$ (95\%CI 92.8-94.8) and $94.3 \%$ (95\%CI 93.3-95.2), pooled specificity of 61.5\% (95\%CI 60.662.7 ) and $51.3 \%(95 \% \mathrm{CI} 50.2-52.4)$, the DOR was 15.96 (95\%CI 10.14-25.17) and 12.55 (95\%CI 92.33-17.07), and the AUC was 0.90 (0.80-1) and 0.91 (0.88-0.95), respectively, for Aptima and Hybrid Capture 2 (Table 3). 
TABLE 3: Accuracy of Aptima for detection of Cervical Intraepithelial Neoplasia (CIN) in histopathological, compared to a DNA hrHPV test (Hybrid Capture 2), in the same sample. Outcome: CIN1- vs. CIN2+.

\begin{tabular}{|c|c|c|}
\hline & $\begin{array}{c}\text { Aptima } \\
\% \text { (IC 95\%) }\end{array}$ & $\begin{array}{c}\text { Hybrid Capture } 2 \\
\% \text { (IC 95\%) }\end{array}$ \\
\hline Sensitivity & $93.9(92.8-94.8)$ & $94.3(93.3-95.2)$ \\
\hline Specificity & $61.7(60.6-62.7)$ & $51.3(50.2-52.4)$ \\
\hline DOR & $15.96(10.14-25.17)$ & $12.55(92.33-17.07)$ \\
\hline AUC & $0.90(0.80-1)$ & $0.91(0.88-0.95)$ \\
\hline $\mathrm{TP}$ & 2,184 & 2,206 \\
\hline FP & 3,243 & 4,092 \\
\hline FN & 143 & 133 \\
\hline $\mathrm{TN}$ & 5,216 & 4,312 \\
\hline$N$ total & 10,786 & 10,743 \\
\hline
\end{tabular}

CIN: cervical intraepithelial neoplasia; CI: Confidence interval; DOR: diagnostic odds ratio; AUC: area under the curve; TP: true positive; FP: false positive; FN: false negative; TN: true negative.

*Small differences between Aptima e HC2 total is due to losses in three studies in HC2 sample: Clad et al., 2011, Monsonego et al., 2011 and Reid et al., 2015.

3.6. Sensitivity Analysis. Discerning by complete verification of the reference test or partial verification, we identified that all samples were biopsied in 38 studies, whereas in 23 studies, they were not (Table 1). In the completely biopsied sample group, the pooled sensitivity was $86.9 \%$ (95\%CI 85.4 88.2 ) and the pooled specificity $64.8 \%$ (95\%CI 63.7-65.8). The DOR was 10.49 (95\%CI 6.94-15.85), and the AUC was 0.85 (95\%CI 0.79-0.92). In contrast, in the partially biopsied sample group in which women with normal colposcopy were not biopsied, the pooled sensitivity was $80.2 \%$ (95\%CI 78.8$81.5)$ and pooled specificity $72.6 \%$ (95\%CI 71.7-73.5). The DOR was 13.96 (95\%CI 9.798-19.91), and the AUC was 0.86 (95\%CI $0.82-0.90)$. This difference is potentially caused by the higher frequency of Aptima studies in the "all biopsied" group, $55.2 \%$ vs. $30.4 \%$, as in comparison, this assay has superior sensitivity, as shown above.

\section{Discussion}

The aim of this systematic review was to evaluate the accuracy of the biomarker HPV mRNA as a means to identify CIN and cervical cancer, a disease with a high prevalence, primarily in low-resource countries. In this analysis, we show 60 studies with the same outcome, making this the most extensive review on the topic to our knowledge.

Two systematic reviews have already been performed analyzing the HPV mRNA test accuracy. Burger et al., in 2011, conducted a systematic review predominately including studies from nonspecific secondary screening [67], and Verdoodt et al., in 2013, included studies with minor abnormal cervical cytology [66]. The first one included 11 studies and concluded that sensitivities ranged from $41.0 \%$ to $86.0 \%$ and from $90.0 \%$ to $95.0 \%$ for the PreTect Proofer/NucliSENS Easy $\mathrm{Q}$ and Aptima assay, respectively. Specificities ranged from $63.0 \%$ to $97.0 \%$ and from $42.0 \%$ to $61.0 \%$ for the same assays, respectively. In our study, the greater number of primary studies led to a wider range of results but maintained the same trend. In a study by Verdoodt et al., which included 10 studies using PreTect Proofer/NucliSENS Easy Q, they concluded that the pooled sensitivity was $75.4 \%$ and $76.2 \%$ and the pooled specificity was $77.9 \%$ and $74.2 \%$, for the triage of ASC-US and LSIL, respectively. These are very close to our results, except that, in our sample, NucliSens EasyQ HPV exhibited a lower specificity.

One of the most promising algorithms is in effect primary screening with the hrHPV DNA test, which has superior sensitivity, and use of the HPV mRNA test, due to its high specificity and the possibility to perform the test with the same sample without the need for patient return. Another possibility is to substitute hrHPV DNA and cytology for HPV mRNA testing. Zappacosta et al., 2015, published a prospective study that compared the cost and effectiveness of three strategies for management of ASC-US and LSIL cytology patients: immediate colposcopy, triage with the hrHPV DNA test, and the HPV mRNA test [79]. They concluded that the HPV mRNA test exhibited overall percentage agreement with histological diagnosis of $89.8 \%$, and as to the AUC, the hrHPV DNA test was 0.79 and the HPV mRNA test 0.92 . Cotesting with HPV DNA and mRNA, in comparison with immediate referral, reduced colposcopy referral by $77.5 \%$ and by $54.5 \%$ in comparison with hrHPV DNA alone. An American study comparing cotesting cytology and hrHPV DNA $(n=1,856)$ or HPV mRNA $(n=1,651)$ in ASC-US cytology samples concluded that the change in the hrHPV detection methodology from $\mathrm{HC} 2$ to Aptima has led to a $21 \%$ reduction in colposcopy referrals and is more cost-effective for patient care [80]. A multicenter trial with 5,006 women undergoing routine screening in France comparing an HPV mRNA test (Aptima), an hrHPV DNA test (HC2), PCR genotyping, and cytology (LBC) already illustrated that Aptima exhibits the highest absolute risk of both histological endpoints and detected 5\% to $15 \%$ more CIN3+ and CIN2+ lesions, respectively, than did cytology. Compared with the HC2 assay, the relative risk of Aptima was $24 \%$ to $29 \%$ higher, with a significant difference in CIN2+ detection, concluding that Aptima is a suitable option for primary cervical cancer screening [81]. In our study, the accuracy was greater for Aptima, when compared to hrHPV DNA tests, suggesting that this could be 
an adequate substitute, especially considering improvements in specificity. In secondary screening, a test with improved specificity would be more useful, like OncoTect or PreTect HPV Profeer.

Great heterogeneity in sensitivity and specificity was found among studies. This could be explained by different samples and different frequencies of CIN in each population. We performed sensitivity analysis using different screening criteria and studies with partial or complete verification of the reference test, to try and detect confounding factors, but the results retained high heterogeneity (data not shown).

In conclusion, this study supports the current hypothesis that HPV mRNA assays are an adequate tool in the secondary screening of cervical cancer.

\section{Additional Points}

Recommendations. Although this systematic review clearly shows the accuracy of HPV mRNA for cervical cancer screening, additional prospective and randomized studies are necessary in order to establish cost-effectiveness and possible changes in screening guidelines.

\section{Disclosure}

The present manuscript had been presented at 6th International Congress on Gynecology \& Gynecologic Oncology (DOI: 10.4172/2161-0932-C2-028), thanks for the contribution and visibility made to this study.

\section{Conflicts of Interest}

The present study has no conflict of interest.

\section{Acknowledgments}

The authors acknowledge generous funding from the University of Extremo Sul Catarinense, Criciúma, SC, Brazil. MIR is a recipient of a CNPQ (Brazil) Productivity Fellowship.

\section{References}

[1] F. Bray, M. Colombet, L. Mery et al., Incidence in Five Continents, vol. XI, International Agency for Research on Cancer, Lyon, France, 2017, http://ci5.iarc.fr.

[2] U.S. Cancer Statistics Working Group, United States Cancer Statistics: 1999-2014 Incidence and Mortality Web-Based Report, Department of Health and Human Services, Centers for Disease Control and Prevention and National Cancer Institute, Atlanta, Ga, USA, 2017, http://www.cdc.gov/uscs.

[3] J. M. Walboomers, M. V. Jacobs, M. M. Manos et al., "Human papillomavirus is a necessary cause of invasive cervical cancer worldwide," The Journal of Pathology, vol. 189, no. 1, pp. 12-19, 1999.

[4] N. Wentzensen, M. Arbyn, J. Berkhof et al., "Eurogin 2016 Roadmap: how HPV knowledge is changing screening practice," International Journal of Cancer, vol. 140, no. 10, pp. 21922200, 2017.
[5] M. Arbyn, P. J. F. Snijders, C. J. L. M. Meijer et al., "Which highrisk HPV assays fulfil criteria for use in primary cervical cancer screening?" Clinical Microbiology and Infection, vol. 21, no. 9, pp. 817-826, 2015.

[6] W. K. Huh, K. A. Ault, D. Chelmow et al., "Use of primary high-risk human papillomavirus testing for cervical cancer screening: interim clinical guidance," Obstetrics \& Gynecology, vol. 125, no. 2, pp. 330-337, 2015.

[7] S. de Sanjose, W. G. Quint, L. Alemany, D. T. Geraets, J. E. Klaustermeier, B. Lloveras et al., "Human papillomavirus genotype attribution in invasive cervical cancer: a retrospective cross-sectional worldwide study," Lancet Oncol, vol. 11, pp. 1048-1056, 2010

[8] M. J. Binnicker, B. S. Pritt, B. J. Duresko et al., "Comparative evaluation of three commercial systems for detection of HighRisk Human papillomavirus in cervical and vaginal ThinPrep PreservCyt samples and correlation with biopsy results," Journal of Clinical Microbiology, vol. 52, no. 10, pp. 3763-3768, 2014.

[9] P. E. Castle, J. Dockter, C. Giachetti et al., "A cross-sectional study of a prototype carcinogenic human papillomavirus E6/E7 messenger RNA assay for detection of cervical precancer and cancer," Clinical Cancer Research, vol. 13, no. 9, pp. 2599-2605, 2007.

[10] P. E. Castle, J. Cuzick, M. H. Stoler et al., "Detection of human papillomavirus 16, 18, and 45 in women with ASC-US cytology and the risk of cervical precancer: Results from the CLEAR HPV study," American Journal of Clinical Pathology, vol. 143, no. 2, pp. 160-167, 2015.

[11] M. Chernesky, D. Jang, N. Escott et al., "Detection of cervical precancerous lesions with Aptima HPV assays using SurePath preservative fluid specimens," Papillomavirus Research, vol. 3, pp. 155-159, 2017.

[12] A. Clad, M. Reuschenbach, J. Weinschenk, R. Grote, J. Rahmsdorf, and N. Freudenberg, "Performance of the aptima high-risk human papillomavirus mRNA assay in a referral population in comparison with hybrid capture 2 and cytology," Journal of Clinical Microbiology, vol. 49, no. 3, pp. 1071-1076, 2011.

[13] K. Cuschieri, H. Cubie, C. Graham et al., "Clinical performance of RNA and DNA based HPV testing in a colposcopy setting: Influence of assay target, cut off and age," Journal of Clinical Virology, vol. 59, no. 2, pp. 104-108, 2014.

[14] J. Cuzick, L. Cadman, D. Mesher et al., "Comparing the performance of six human papillomavirus tests in a screening population," British Journal of Cancer, vol. 108, no. 4, pp. 908913, 2013.

[15] J. Dockter, A. Schroder, C. Hill, L. Guzenski, J. Monsonego, and C. Giachetti, "Clinical performance of the APTIMA HPV Assay for the detection of high-risk HPV and high-grade cervical lesions," Journal of Clinical Virology, vol. 45, no. 1, pp. S55-S61, 2009.

[16] Y. Ge, P. Christensen, E. Luna, D. Armylagos, M. R. Schwartz, and D. R. Mody, "Performance of aptima and cobas HPV testing platforms in detecting high-grade cervical dysplasia and cancer," Cancer Cytopathology, vol. 125, no. 8, pp. 652-657, 2017.

[17] Y. Ge, P. Christensen, E. Luna et al., "Aptima human papillomavirus E6/E7 mRNA test results strongly associated with risk for high-grade cervical lesions in follow-up biopsies," Journal of Lower Genital Tract Disease, vol. 22, no. 3, pp. 195-200, 2018.

[18] Y. Guo, K. You, L. Geng, and J. Qiao, "The clinical performance of APTIMA human papillomavirus and hybrid capture 2 assays in the triage of lesser abnormal cervical cytologies," Journal of Gynecologic Oncology, vol. 25, no. 4, pp. 287-292, 2014. 
[19] T. Iftner, S. Becker, K.-J. Neis et al., "Head-to-head comparison of the RNA-based aptima human papillomavirus (HPV) assay and the DNA-based hybrid capture $2 \mathrm{HPV}$ test in a routine screening population of women aged 30 to 60 years in Germany," Journal of Clinical Microbiology, vol. 53, no. 8, pp. 25092516, 2015.

[20] H. Johansson, K. Bjelkenkrantz, L. Darlin, J. Dilllner, and O. Forslund, "Presence of high-risk HPV mRNA in relation to future high-grade lesions among high-risk HPV DNA positive women with minor cytological abnormalities," PLOS ONE, vol. 10, no. 4, Article ID e0124460, 2015.

[21] J. Monsonego, M. G. Hudgens, L. Zerat et al., "Evaluation of oncogenic human papillomavirus RNA and DNA tests with liquid-based cytology in primary cervical cancer screening: the FASE study," International Journal of Cancer, vol. 129, no. 3, pp. 691-701, 2011.

[22] T. Muangto, A. Chanthasenanont, S. Lertvutivivat et al., "Experience of combined liquid based cervical cytology and highrisk HPV mRNA for cervical cancer screening in Thammasat university hospital," Asian Pacific Journal of Cancer Prevention, vol. 17, no. 9, pp. 4409-4413, 2016.

[23] I. T. Ovestad, U. Vennestrøm, L. Andersen et al., "Comparison of different commercial methods for HPV detection in followup cytology after ASCUS/LSIL, prediction of CIN2-3 in follow up biopsies and spontaneous regression of CIN2-3," Gynecologic Oncology, vol. 123, no. 2, pp. 278-283, 2011.

[24] M. Persson, K. M. Elfström, S. B. Wendel, E. Weiderpass, and S. Andersson, "Triage of HR-HPV positive women with minor cytological abnormalities: A comparison of mRNA testing, HPV DNA testing, and repeat cytology using a 4-year followup of a population-based study," PLoS ONE, vol. 9, no. 2, Article ID e90023, 2014.

[25] S. Ratnam, D. Fontaine, F. Coutlee et al., "HPV E6/E7 mRNA and MCM2/TOP2a testing in cervical cancer screening: results from a multicentre Canadian study," International Journal of Antimicrobial Agents, vol. 34, pp. S22-S23, 2009.

[26] S. Ratnam, F. Coutlee, D. Fontaine et al., "Aptima HPV E6/E7 mRNA test is as sensitive as hybrid capture 2 assay but more specific at detecting cervical precancer and cancer," Journal of Clinical Microbiology, vol. 49, no. 2, pp. 557-564, 2011.

[27] M. Rebolj, E. Lynge, D. Ejegod, S. Preisler, C. Rygaard, and J. Bonde, "Comparison of three human papillomavirus DNA assays and one mRNA assay in women with abnormal cytology," Gynecologic Oncology, vol. 135, no. 3, pp. 474-480, 2014.

[28] J. L. Reid, T. C. Wright, M. H. Stoler et al., "Human papillomavirus oncogenic mRNA testing for cervical cancer screening: Baseline and longitudinal results from the CLEAR study," American Journal of Clinical Pathology, vol. 144, no. 3, pp. 473483, 2015.

[29] M. Reuschenbach, A. Clad, C. Von Knebel Doeberitz et al., "Performance of p16INK4a-cytology, HPV mRNA, and HPV DNA testing to identify high grade cervical dysplasia in women with abnormal screening results," Gynecologic Oncology, vol. 119, no. 1, pp. 98-105, 2010.

[30] M. H. Stoler, T. C. Wright Jr., J. Cuzick et al., "APTIMA HPV assay performance in women with atypical squamous cells of undetermined significance cytology results," American Journal of Obstetrics \& Gynecology, vol. 208, no. 2, pp. 144.e1-148.e1, 2013.

[31] A. Szarewski, D. Mesher, L. Cadman et al., "Comparison of seven tests for high-grade cervical intraepithelial neoplasia in women with abnormal smears: the predictors 2 study," Journal of Clinical Microbiology, vol. 50, no. 6, pp. 1867-1873, 2012.

[32] E. Virtanen, I. Kalliala, T. Dyba, P. Nieminen, and E. Auvinen, "Performance of mRNA- and DNA-based high-risk human papillomavirus assays in detection of high-grade cervical lesions," Acta Obstetricia et Gynecologica Scandinavica, vol. 96, no. 1, pp. 61-68, 2017.

[33] M. Waldstrom and D. Ornskov, "Comparison of the clinical performance of an HPV mRNA test and an HPV DNA test in triage of atypical squamous cells of undetermined significance (ASC-US)," Cytopathology, vol. 23, no. 6, pp. 389-395, 2012.

[34] M. Waldstrøm, R. K. Christensen, and D. Ornskov, "Evaluation of pl6INK4a/Ki-67 dual stain in comparison with an mRNA human papillomavirus test on liquid-based cytology samples with low-grade squamous intraepithelial lesion," Cancer Cytopathology, vol. 121, no. 3, pp. 136-145, 2013.

[35] R. Wu, S. E. Belinson, H. Du et al., "Human papillomavirus messenger RNA assay for cervical cancer screening: the Shenzhen cervical cancer screening trial I," International Journal of Gynecological Cancer, vol. 20, pp. 1411-1414, 2010.

[36] S. Andersson, B. Hansson, I. Norman et al., "Expression of E6/E7 mRNA from 'high risk' human papillomavirus in relation to CIN grade, viral load and p16INK4a," International Journal of Oncology, vol. 29, no. 3, pp. 705-711, 2006.

[37] P. Cattani, G. F. Zannoni, C. Ricci et al., "Clinical performance of human papillomavirus E6 and E7 mRNA testing for high-grade lesions of the cervix," Journal of Clinical Microbiology, vol. 47, no. 12, pp. 3895-3901, 2009.

[38] S. Duvlis, K. Popovska-Jankovic, Z. S. Arsova, S. Memeti, Z. Popeska, and D. Plaseska-Karanfilska, "HPV E6/E7 mRNA versus HPV DNA biomarker in cervical cancer screening of a group of Macedonian women," Journal of Medical Virology, vol. 87, no. 9, pp. 1578-1586, 2015.

[39] B. Galarowicz, R. Jach, J. Kidzierska et al., "The role of mRNA E6/E7 HPV high oncogenic risk expression in colposcopy of cervical intraepithelial neoplasia (CIN).," Przegląd Lekarski, vol. 69, no. 9, pp. 651-657, 2012.

[40] P. Halfon, D. Benmoura, A. Agostini et al., "Relevance of HPV mRNA detection in a population of ASCUS plus women using the NucliSENS EasyQ HPV assay," Journal of Clinical Virology, vol. 47, no. 2, pp. 177-181, 2010.

[41] G. Koliopoulos, C. Chrelias, A. Pappas et al., "The diagnostic accuracy of two methods for E6\&7 mRNA detection in women with minor cytological abnormalities," Acta Obstetricia et Gynecologica Scandinavica, vol. 91, no. 7, pp. 794-801, 2012.

[42] A. Oliveira, N. Verdasca, and Â. Pista, "Use of the NucliSENS EasyQ HPV assay in the management of cervical intraepithelial neoplasia," Journal of Medical Virology, vol. 85, no. 7, pp. 12351241, 2013.

[43] E. Padalko, L. Van Renterghem, M. Bamelis et al., "Prospective evaluation of E6/E7 mRNA detection by the NucliSENS Easy Q HPV assay in a stepwise protocol," Journal of Medical Virology, vol. 85, no. 7, pp. 1242-1249, 2013.

[44] S. P. Castro, A. I. Fernández, M. J. L. González et al., "Human papillomavirus (HPV) E6/E7 mRNA as a triage test after detection of HPV 16 and HPV 18 DNA," Journal of Medical Virology, vol. 85, no. 6, pp. 1063-1068, 2013.

[45] C. Ren, Y. Zhu, L. Yang, X. Zhang, L. Liu, and C. Ren, "Diagnostic performance of HPV E6/E7 mRNA assay for detection of cervical high-grade intraepithelial neoplasia and cancer among women with ASCUS Papanicolaou smears," Archives of Gynecology and Obstetrics, vol. 297, no. 2, pp. 425-432, 2018. 
[46] J. Valença, A. Gonçalves, I. Guerreiro da Silva et al., "High risk HPV E6/E7 oncoprotein expression in women with high grade squamous intraepithelial lesion," RBGO Gynecology and Obstetrics, vol. 38, no. 03, pp. 154-159, 2016.

[47] G. Coquillard, B. Palao, and B. K. Patterson, "Quantification of intracellular HPV E6/E7 mRNA expression increases the specificity and positive predictive value of cervical cancer screening compared to HPV DNA," Gynecologic Oncology, vol. 120, no. 1, pp. 89-93, 2011.

[48] C. Kottaridi, S. Tsiodras, A. Spathis et al., "Clinical performance of human papillomavirus E6, E7 mRNA flow cytometric assay compared to human papillomavirus DNA typing," Anal Quant Cytol Histol, vol. 33, pp. 305-310, 2011.

[49] D. Pierry, G. Weiss, B. Lack, V. Chen, and J. Fusco, "Intracellular human papillomavirus E6, E7 mRNA quantification predicts CIN 2+ in cervical biopsies better than papanicolaou screening forwomen regardless of age," Archives of Pathology \& Laboratory Medicine, vol. 136, no. 8, pp. 956-960, 2012.

[50] V. Stathopoulou, G. Koliopoulos, D. Zygouris et al., "The diagnostic accuracy of E6 \& 7 mRNA detection as a primary screening test for the detection of severe cervical lesions," Journal of B.U.ON., vol. 19, no. 2, pp. 490-496, 2014.

[51] G. Valasoulis, S.-M. Stasinou, M. Nasioutziki et al., "Expression of HPV-related biomarkers and grade of cervical intraepithelial lesion at treatment," Acta Obstetricia et Gynecologica Scandinavica, vol. 93, no. 2, pp. 194-200, 2014.

[52] R. Alaghehbandan, D. Fontaine, J. Bentley et al., "Performance of ProEx c and PreTect HPV-Proofer E6/E7 MRNA tests in comparison with the Hybrid Capture $2 \mathrm{HPV}$ DNA test for triaging ASCUS and LSIL cytology," Diagnostic Cytopathology, vol. 41, no. 9, pp. 767-775, 2013.

[53] M. Benevolo, A. Vocaturo, D. Caraceni et al., "Sensitivity, specificity, and clinical value of human papillomavirus (HPV) E6/E7 mRNA assay as a triage test for cervical cytology and HPV DNA test," Journal of Clinical Microbiology, vol. 49, pp. 2643-2650, 2011.

[54] S. Hovland, M. Arbyn, A. K. Lie et al., "A comprehensive evaluation of the accuracy of cervical pre-cancer detection methods in a high-risk area in East Congo," British Journal of Cancer, vol. 102, no. 6, pp. 957-965, 2010.

[55] A. K. Lie, B. Risberg, B. Borge et al., "DNA- versus RNAbased methods for human papillomavirus detection in cervical neoplasia," Gynecologic Oncology, vol. 97, no. 3, pp. 908-915, 2005.

[56] T. Molden, I. Kraus, F. Karlsen, H. Skomedal, J. F. Nygård, and B. Hagmar, "Comparison of human papillomavirus messenger RNA and DNA detection: a cross-sectional study of 4,136 women $>30$ years of age with a 2-year follow-up of highgrade squamous intraepithelial lesion," Cancer Epidemiology, Biomarkers \& Prevention, vol. 14, no. 2, pp. 367-372, 2005.

[57] S. Ratnam, F. Coutlee, D. Fontaine et al., "Clinical performance of the PreTect HPV-proofer E6/E7 mRNA assay in comparison with that of the hybrid capture 2 test for identification of women at risk of cervical cancer," Journal of Clinical Microbiology, vol. 48, no. 8, pp. 2779-2785, 2010.

[58] S. W. Sorbye, M. Arbyn, S. Fismen, T. J. Gutteberg, and E. S. Mortensen, "Triage of women with Low-Grade cervical lesions - HPV mRNA testing versus repeat cytology," PLoS ONE, vol. 6, no. 8, p. e24083, 2011.

[59] A. Tropé, K. Sjøborg, A. Eskild et al., "Performance of human papillomavirus DNA and mRNA testing strategies for women with and without cervical neoplasia," Journal of Clinical Microbiology, vol. 47, no. 8, pp. 2458-2464, 2009.

[60] A. Tropé, K. D. Sjøborg, M. Nygård et al., "Cytology and human papillomavirus testing 6 to 12 months after ASCUS or LSIL cytology in organized screening to predict highgrade cervical neoplasia between screening rounds," Journal of Clinical Microbiology, vol. 50, no. 6, pp. 1927-1935, 2012.

[61] B. Westre, A. Giske, H. Guttormsen, S. W. Sørbye, and F. E. Skjeldestad, "5-type HPV mRNA versus 14-type HPV DNA test: Test performance, over-diagnosis and overtreatment in triage of women with minor cervical lesions," BMC Clinical Pathology, vol. 16, no. 1, article no. 9, 2016.

[62] Y. Li, S. Rong, Y. Zhi, C. Qiu, T. Fan, and X. Li, "Detection of cervical intraepithelial neoplasia with HPVE6/E7 mRNA among women with atypical squamous cells of unknown significance," International Journal of Gynecology and Obstetrics, vol. 137, no. 2, pp. 145-149, 2017.

[63] T.-Y. Liu, R. Xie, L. Luo et al., "Diagnostic validity of human papillomavirus E6/E7 mRNA test in cervical cytological samples," Journal of Virological Methods, vol. 196, pp. 120-125, 2014.

[64] L. Liu, Q. Zhang, Y. Chen, and F. Guo, "Role of E6/E7 mRNA in discriminating patients with high-risk Human papilloma viruspositive associated with cytology-negative and atypical squamous cells of undetermined significance," Biomedical Research (India), vol. 28, no. 9, pp. 3986-3990, 2017.

[65] Y. Shen, J. Gong, Y. He, G. Cheng, P. Okunieff, and X. Li, "Quantivirus ${ }^{\circledR}$ HPV E6/E7 RNA 3.0 assay (bDNA) is as sensitive, but less specific than Hybrid Capture 2 test," Journal of Virological Methods, vol. 187, no. 2, pp. 288-293, 2013.

[66] F. Verdoodt, A. Szarewski, P. Halfon, K. Cuschieri, and M. Arbyn, "Triage of women with minor abnormal cervical cytology: Meta-analysis of the accuracy of an assay targeting messenger ribonucleic acid of 5 high-risk human papillomavirus types," Cancer Cytopathology, vol. 121, no. 12, pp. 675-687, 2013.

[67] E. A. Burger, H. Kornør, M. Klemp, V. Lauvrak, and I. S. Kristiansen, "HPV mRNA tests for the detection of cervical intraepithelial neoplasia: a systematic review," Gynecologic Oncology, vol. 120, no. 3, pp. 430-438, 2011.

[68] P. F. Whiting, A. W. S. Rutjes, M. E. Westwood et al., "Quadas-2: a revised tool for the quality assessment of diagnostic accuracy studies," Annals of Internal Medicine, vol. 155, no. 8, pp. 529-536, 2011.

[69] B. Littenberg and L. E. Moses, "Estimating diagnostic accuracy from multiple conflicting reports," Medical Decision Making, vol. 13, no. 4, pp. 313-321, 2016.

[70] J. B. Reitsma, A. S. Glas, A. W. S. Rutjes, R. J. P. M. Scholten, P. M. Bossuyt, and A. H. Zwinderman, "Bivariate analysis of sensitivity and specificity produces informative summary measures in diagnostic reviews," Journal of Clinical Epidemiology, vol. 58, no. 10, pp. 982-990, 2005.

[71] C. M. Jones and T. Athanasiou, "Summary receiver operating characteristic curve analysis techniques in the evaluation of diagnostic tests," The Annals of Thoracic Surgery, vol. 79, no. 1, pp. 16-20, 2005.

[72] Review Manager (RevMan) [Computer program]. Version 5.3. Copenhagen: The Nordic Cochrane Centre, The Cochrane Collaboration, 2014.

[73] J. Zamora, V. Abraira, A. Muriel, K. Khan, and A. Coomarasamy, "Meta-DiSc: a software for meta-analysis of test accuracy data," BMC Medical Research Methodology, vol. 6, article no. 31, 2006. 
[74] M. F. Evans, Z. Peng, K. M. Clark et al., "HPV E6/E7 RNA In situ hybridization signal patterns as biomarkers of three-tier cervical intraepithelial neoplasia grade," PLoS ONE, vol. 9, no. 3, Article ID e91142, 2014.

[75] İ. Tuney, A. Altay, K. Ergunay et al., "HPV types and E6/E7 mRNA expression in cervical samples from Turkish women with abnormal cytology in Ankara, Turkey," Turkish Journal of Medical Sciences, vol. 47, pp. 194-200, 2017.

[76] W. Rokita, W. Kedzia, D. Pruski et al., "Comparison of the effectiveness of cytodiagnostics, molecular identification of HPV HR and cintecplus ${ }^{\mathrm{TM}}$ test to identify LG SIL and HG SIL," Ginekologia Polska, vol. 83, no. 12, pp. 894-898, 2012.

[77] J. Haedicke and T. Iftner, "A review of the clinical performance of the Aptima HPV assay," Journal of Clinical Virology, vol. 76, pp. S40-S48, 2016.

[78] D. Jeantet, F. Schwarzmann, J. Tromp et al., "NucliSENS ${ }^{\circledR}$ EasyQ ${ }^{\circledR} \mathrm{HPV}$ v1 test - testing for oncogenic activity of human papillomaviruses," Journal of Clinical Virology, vol. 45, no. 1, pp. S29-S37, 2009.

[79] R. Zappacosta, D. M. P. Gatta, P. Marinucci et al., "Role of E6/E7 mRNA test in the diagnostic algorithm of HPV-positive patients showing ASCUS and LSIL: clinical and economic implications in a publicly financed healthcare system," Expert Review of Molecular Diagnostics, vol. 15, no. 1, pp. 137-150, 2015.

[80] J. L. Sauter, S. L. Mount, T. L. St. John, C. M. Wojewoda, R. J. Bryant, and G. Leiman, "Testing of integrated human papillomavirus mrna decreases colposcopy referrals: Could a change in human papillomavirus detection methodology lead to more cost-effective patient care?" Acta Cytologica, vol. 58, no. 2, pp. 162-166, 2014.

[81] J. Monsonego, M. G. Hudgens, L. Zerat, J.-C. Zerat, K. Syrjänen, and J. S. Smith, "Risk assessment and clinical impact of liquidbased cytology, oncogenic human papillomavirus (HPV) DNA and mRNA testing in primary cervical cancer screening (The FASE Study)," Gynecologic Oncology, vol. 125, no. 1, pp. 175-180, 2012. 


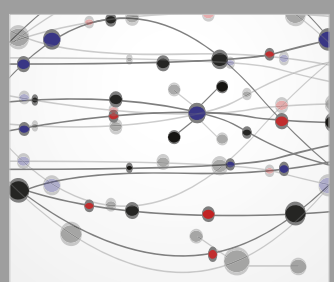

The Scientific World Journal
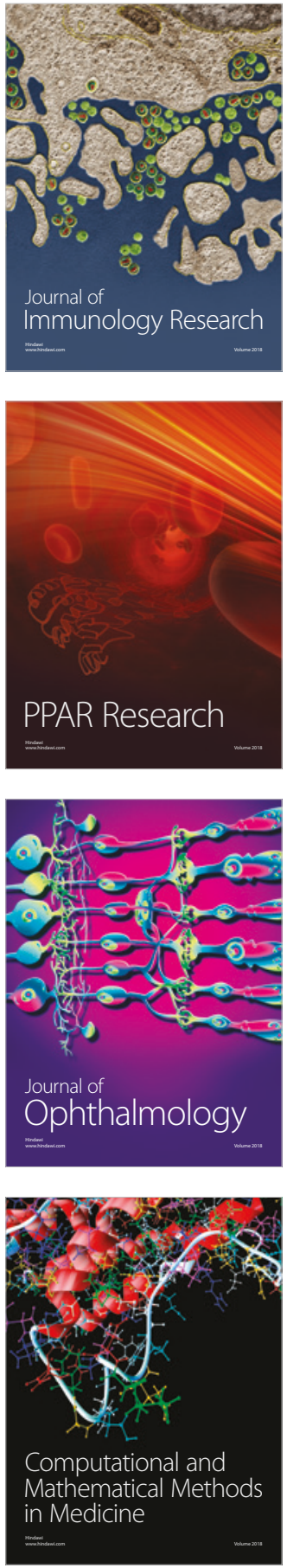

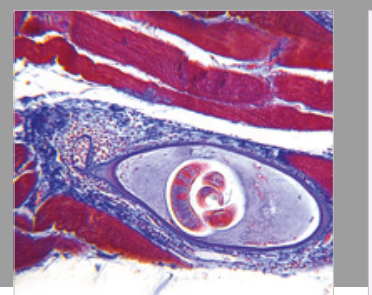

Gastroenterology Research and Practice

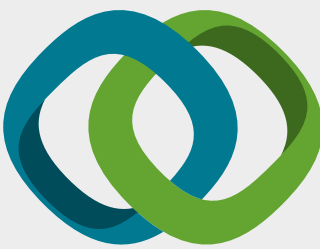

\section{Hindawi}

Submit your manuscripts at

www.hindawi.com
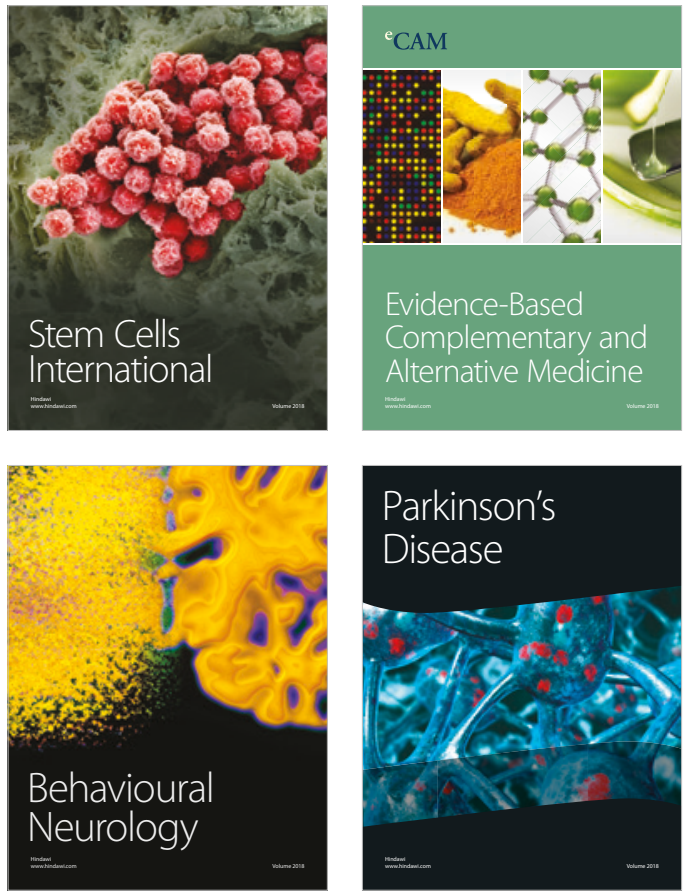

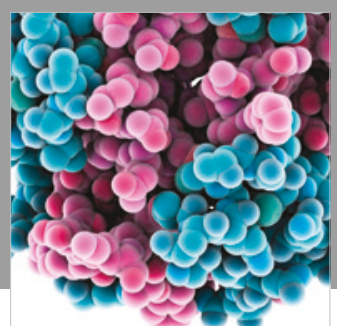

ournal of

Diabetes Research

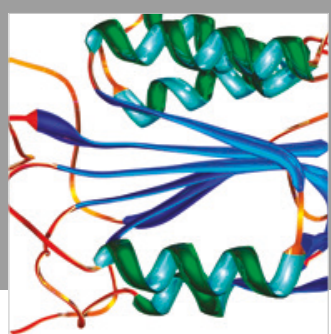

Disease Markers
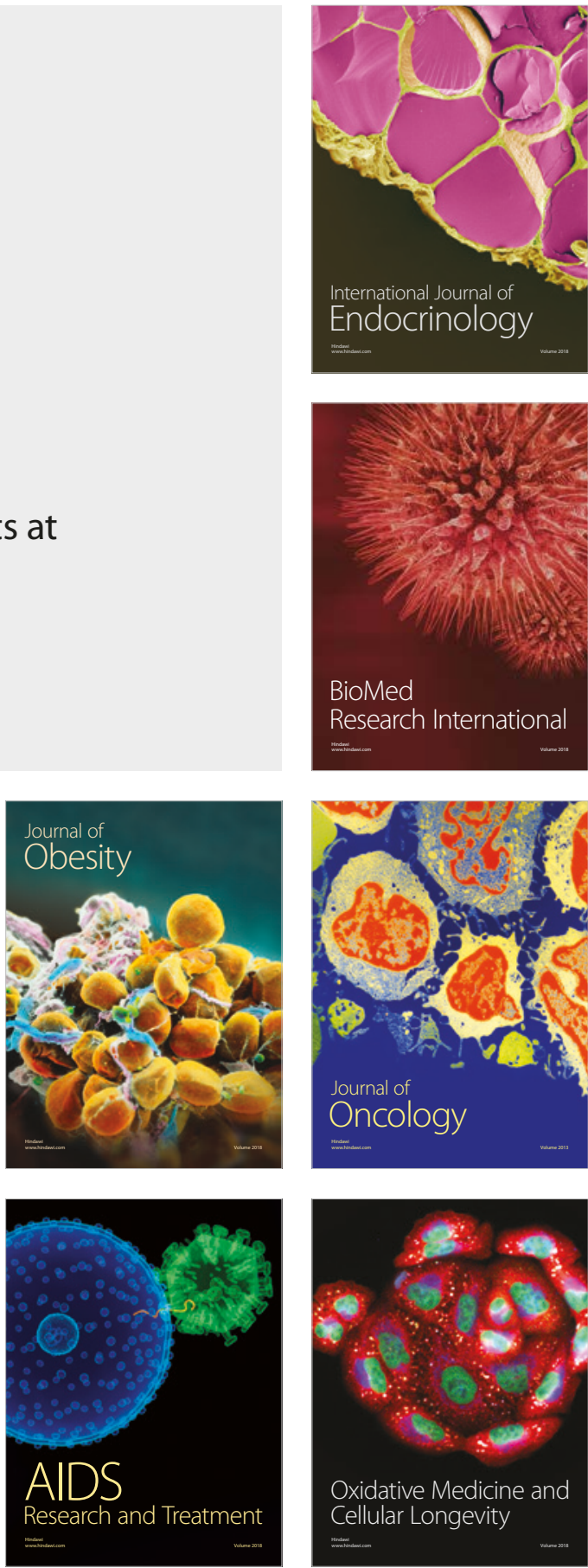